\title{
Effects of catecholamines on volemic replacement with saline solution and the impact on heart rate variability in rabbits subjected to hemorrhage. A study by spectral analysis ${ }^{1}$
}

\author{
José Mariano Soares de Moraes ${ }^{\mathrm{I}}$, Matheus Fachini Vane ${ }^{\mathrm{II}}$, Denise de Fátima Rodrigues ${ }^{\mathrm{III}}$, Cristiano Teixeira Mostarda ${ }^{\mathrm{IV}}$, Thiago \\ Soares Mendes Moreira de Moraesv, Lucas Fachini Vane ${ }^{\mathrm{VI}}$, Eliana Marisa Ganem ${ }^{\mathrm{VII}}$, Ismar Lima Cavalcanti ${ }^{\mathrm{VIII}}$, Norma Sueli \\ Pinheiro Módolo ${ }^{\mathrm{IX}}$, Luiz Antonio Vane ${ }^{\mathrm{X}}$
}

DOI: http://dx.doi.org/10.1590/S0102-86502014001800002

IFellow PhD degree, Postgraduate Program in Anesthesiology, Botucatu Medical School, Sao Paulo State University (UNESP), Brazil. Conception, design, intellectual and scientific content of the study.

${ }^{I I M D, ~ D i v i s i o n ~ o f ~ A n e s t h e s i o l o g y, ~ M e d i c a l ~ S c h o o l, ~ U n i v e r s i t y ~ o f ~ S a o ~ P a u l o ~(U S P), ~ B r a z i l . ~ M a n u s c r i p t ~ w r i t i n g . ~}$

IIIPhD, Division of Veterinary Anesthesiology, UNESP, Brazil. Surgical procedures, acquisition of data.

${ }^{\text {IV }} \mathrm{PhD}$, Heart Institute (InCor), USP, Sao Paulo-SP, Brazil. Heart rate variability and spectral analysis.

${ }^{\mathrm{v}} \mathrm{MD}$, Division of Anesthesiology, Juiz de Fora Medical and Health School (SUPREMA), Brazil. Acquisition and interpretation of data.

${ }^{\mathrm{VI} M a s t e r, ~ M e c h a n i c a l ~ E n g i n e e r, ~ G u a r a t i n g u e t a ~ S c h o o l ~ o f ~ E n g i n e e r i n g, ~ U N E S P, ~ B r a z i l . ~ M a n u s c r i p t ~ w r i t i n g . ~}$

${ }^{V I I}$ Full Professor, Department of Anesthesiology, Botucatu Medical School, UNESP, Brazil. Critical revision.

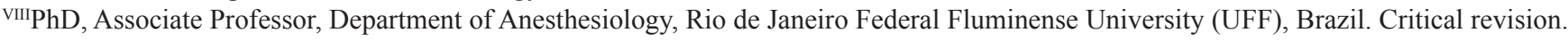

${ }^{\mathrm{IX}}$ Full Professor, Department of Anesthesiology, Botucatu Medical School, UNESP, Brazil. Critical revision.

${ }^{\mathrm{x}}$ Full Professor, Department of Anesthesiology, Botucatu Medical School, UNESP, Brazil. Supervised all phases of the study, manuscript writing, critical revision.

\section{ABSTRACT}

PURPOSE: To verify the effects of different catecholamines on volemic expansion and on the autonomic nervous system in rabbits that were subjected to hemorrhage.

METHODS: Twenty four rabbits subjected to hemorrhage (with a 25\% loss of blood volume) and were randomly divided into four experimental groups: 1) HEMO Group underwent replacement with their own blood in an equal volume; 2) SS Group underwent replacement with saline solution (SS) in a volume that corresponded to three times the removed blood volume; 3) ISP Group underwent replacement with SS and isoprenaline; 4) FNL Group underwent replacement with SS and phenylephrine. Spectral Analysis of the heart rate and heart rate variability were performed from the recorded data. Hematocrit was measured throughout the experiment.

RESULTS: Replacement with SS and an $\alpha$ - or $\beta$-agonist did not produce differences in the intravascular retention compared to replacement with SS alone. An analysis of HRV showed that the FNL group maintained the LF/HF ratio better than ISP and SS.

CONCLUSIONS: No difference in vascular retention when $\alpha$ - or $\beta$ - agonists were added to SS during post-hemorrhagic recovery. The animals in the FNL group maintained the integrity of the autonomic response within normal physiological standards during hemorrhagic stress.

Key words: Catecholamines. Adrenergic alpha-Agonists. adrenergic beta-Agonists. Blood Volume. Hemorrhage. Autonomic Nervous System. Rabbits. 


\section{Introduction}

The infusion of crystalloid solutions and adrenergic drugs are routine procedures for patients undergoing anesthetic surgical procedures because they are safe and low-cost $t^{1,2}$. The crystalloids have little effect on volemic expansion because only $20 \%$ of the total quantity that is infused remains in the intravascular space 20 minutes after infusion. Half of the infused volume is eliminated as urine, and $30 \%$ causes edema ${ }^{3-6}$.

This result is more evident when a large volume of crystalloids is infused during major surgery, which results in a highly positive fluid balance. For many patients, this increase in plasmatic and interstitial volume is well tolerated due to the compensatory cardiovascular response, with an increase in the production of urine and the formation of transitory edema, both of which involve few functional consequences for patients.

In some situations, pure crystalloid solutions do not provide sufficient perfusion to guarantee good oxygenation of tissues. Furthermore, vasoactive drugs with inotropic or vasopressor properties are sometimes used in combination with crystalloid infusion to improve the cardiovascular response to volume overload. Despite our wide-ranging knowledge of the effects of volume overload on the cardiovascular system and the usefulness of hemodynamic parameters as indicators of the level of hydration and the intravascular volume of patients, the same cardiovascular response to volume overload does not occur in the presence of catecholamines.

Adrenergic drugs directly stimulate the myocardial fibers through specific adrenergic receptors. These effects are also exerted by changes in the distribution and elimination of the infused liquids ${ }^{6}$.

Until recently, volume expansion and inotropic support were thought to have different and independent mechanisms. However, Vane et $a l^{6}{ }^{6}$ demonstrated that volemic replacement with crystalloid solutions and $\beta$-agonists produced a greater intravascular retention of these solutions when they were used in conscious and normovolemic sheep.

Furthermore, alterations in intravascular volume, which is mainly associated with the infusion of adrenergic drugs, have been found to considerably alter autonomic cardiovascular modulation through actions on the sympathetic and parasympathetic systems. In addition, an evaluation of the actions of the autonomic nervous system (ANS) on the cardiovascular system using spectral analysis can be performed under anesthesia because it is a non-invasive and low-cost technique ${ }^{7-10}$.

Based on these data, we investigated how volemic replacement with large volumes of saline solution in combination with $\alpha$ - and $\beta$-agonist catecholamines affected vascular retention and HRV in animals that had been subjected to hemorrhage.

\section{Methods}

The present study was approved by the Ethics Committee on Animal Experimentation of the Department of Medicine of Botucatu of Paulista State University "Júlio de Mesquita Filho".

We used 24 rabbits with weights that varied between 2.9 and $4.5 \mathrm{~kg}$ (mean $=3.6 \pm 0.50 \mathrm{~kg})$. The animals were pre-medicated with xylazine $\left(0.5 \mathrm{mg} \mathrm{kg}^{-1}\right)$ and ketamine $\left(10 \mathrm{mg} \mathrm{kg}^{-1}\right)$. We performed a tracheostomy using a 3-mm tracheal probe, and controlled mechanical ventilation was installed (Datex Ohmeda ventilator model 7900) using a current volume of $8 \mathrm{ml} / \mathrm{kg}$. The ventilation frequency was adjusted for an $\mathrm{EtCO}_{2}$ of $25 \mathrm{mmHg}$ (Datex Engstrom AS3). Anesthesia was maintained with isoflurane at a concentration of $1.5 \%$ to $3 \%$.

After this procedure, we dissected the left carotid and right femoral arteries of the right jugular vein and performed a bladder cystostomy. Once the surgical preparation was completed, we allowed a 15-minute period of observation to allow the hemodynamic variables to stabilize. Concomitantly, we began hydration maintenance with saline solution at a dose of $3 \mathrm{ml} \mathrm{kg}$ $\mathrm{h}^{-1}$, which was continued until the end of the experiment.

After the observation period, the hemorrhagic period began, lasting 10 minutes and consisting of removal of $25 \%$ of the blood volume, which was calculated based on a concentration of $57 \mathrm{ml} \mathrm{kg}^{-1}$. The bleeding was performed at a speed of $5 \mathrm{ml}$ of blood/minute.

Volemic replacement was measured over a period of 20 minutes and depended on the group to which the animal belonged. We created four experimental groups with six animals in each group; the groups were defined as follows.

The HEMO Group underwent volemic replacement with the rabbit's own blood at the same volume as the blood that was withdrawn.

The SS Group underwent replacement with a crystalloid solution (saline solution $0.9 \%$ ) in a volume that corresponded to three times the volume of blood that had been withdrawn.

The ISP Group underwent replacement with a crystalloid solution (saline solution $0.9 \%$ ) in a volume that corresponded to three times the volume of blood that was withdrawn combined with an infusion of $0.1 \mu \mathrm{g}$ isoprenaline $\mathrm{kg}^{-1} \mathrm{~min}^{-1}$.

The FNL Group underwent replacement with a crystalloid solution (saline solution $0.9 \%$ ) in a volume that corresponded to three times the volume of blood that was withdrawn combined with an infusion of phenylephrine at a dose of $3.0 \mu \mathrm{g} \mathrm{kg}^{-1} \mathrm{~min}^{-1}$.

\section{Experimental procedures}

Over the course of the entire experiment, we recorded the following variables: heart rate (HR) and hematocrit (Htc). The 
following variables were recorded at the following times:

Basal (MB) - 15 minutes after the conclusion of surgical preparation;

Hemorrhagic $(\mathrm{MH})$ - 10 minutes after the beginning of hemorrhage;

Catecholamines (MC) - 10 minutes after the beginning of the infusion of catecholamine;

Replacement (MR) - 20 minutes after the beginning of volemic replacement; and

Final (MF) - 90 minutes after the conclusion of volemic replacement.

TABLE 1 - Times and periods for events in the study.

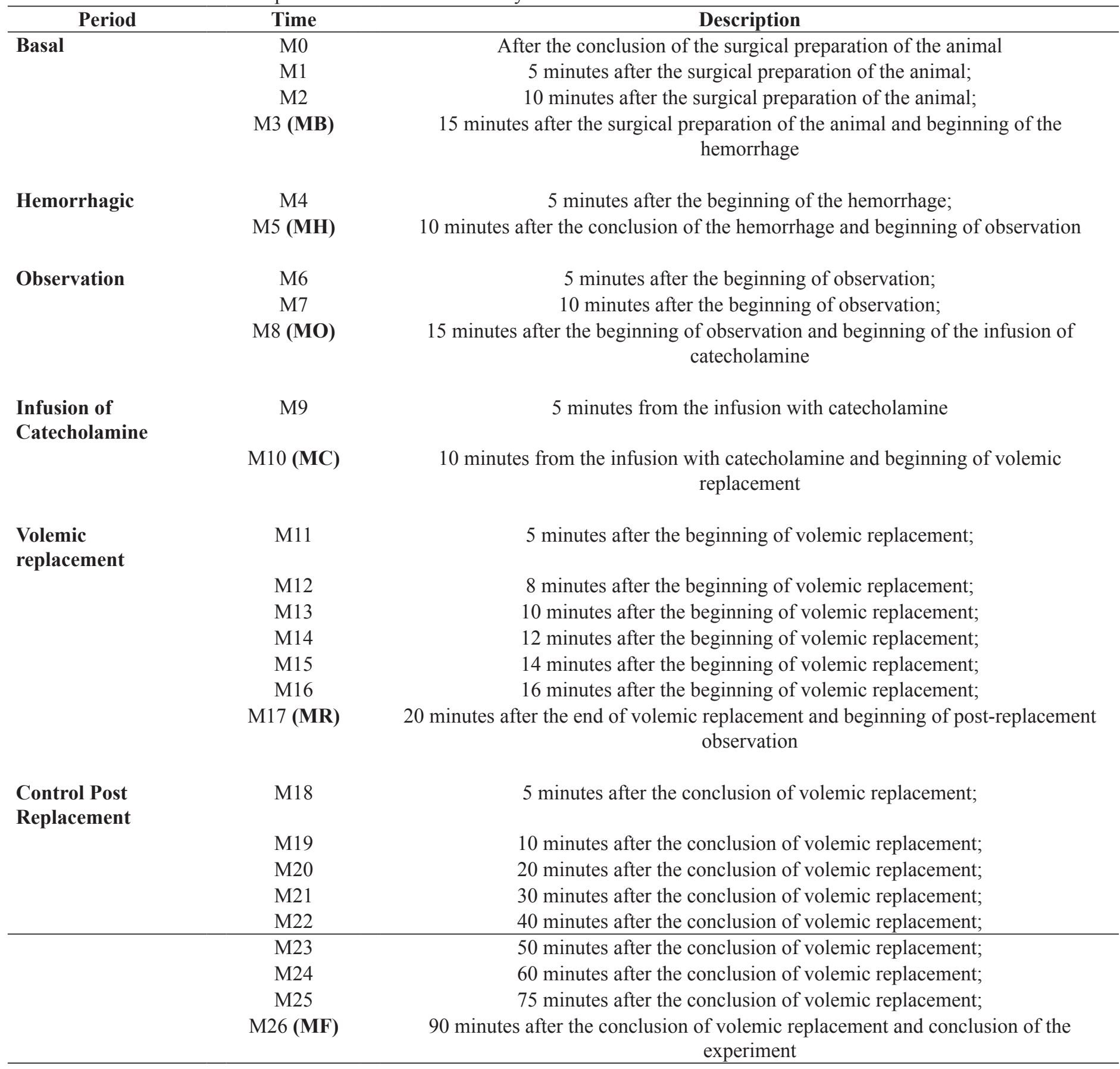

In addition, we continuously recorded the HRV using spectral analysis in the frequency domain. From this recording, we delineated the following sections for definition:

Basal - for 15 minutes, initiated after the preparation of complicated surgery; Hemorrhagic - for 10 minutes during the hemorrhage;

Catecholamine - for 10 minutes after the beginning of the infusion of catecholamines and before the beginning of volemic replacement;

Control - for 90 minutes after the conclusion of volemic replacement (Table 1). 
After the conclusion of the experiment, the animals were killed with an overdose of inhaled anesthesia and the administration of intravenous sodium thiopental.

\section{Collection of data}

\section{$\underline{\text { Hematocrit }}$}

To measure the hematocrit, we collected blood from the right femoral artery in two capillary tubes, which were sealed and spun by micro centrifuge (FANEM MOD. 211). Hematocrit was measured at each time point during the study, and the value of the hematocrit was the average value obtained for the two capillary tubes.

\section{Heart rate variability (HRV)}

For study of the HRV, we used the curve for pulsatile arterial pressure (PAP). Recordings of PAP were performed during the entire experiment to obtain the RR intervals in all of the experimental groups. For this procedure, we connected the arterial cannula to a polyethylene tube (PE 2), and the tube was connected to an electromagnetic transducer (Kent Instruments), which was connected to an amplifier (General Purpose Amplifier, Stemtech, Inc.). The analog signal that was obtained for arterial pressure was converted to a digital signal and recorded in real time with a sampling frequency of 2000 $\mathrm{Hz}$ on a microcomputer with the DataQ/Windaq system. For the analysis of the data, each heartbeat was identified using an algorithm in DataQ/Windaq that automatically detected the RR intervals in the PA wave. Through use of the fast Fourier transform (FFT) implemented in a specific program for calculations (MATLAB 6.0), we generated a spectrum of frequencies. The frequency band of interest for spectral analysis in rabbits is in the interval between 0 and $0.5625 \mathrm{~Hz}$. These frequencies were divided into high frequency (HF), low frequency (LF) and very low frequency of variability (VLF) of HRV. To elucidate the influence of the spectral components on the HR, we used normalized units (\%) that represent the relative power of each component in proportion to the total power minus the VLF component.

\section{Statistical analysis}

For analysis of the data, we used an analysis of variance (ANOVA) with double entry. When there was a significant $(p<0.05)$ interaction between the factors $(F)$, we used a post hoc Bonferroni test to verify the differences between moments and groups and the Kruskal-Wallis test to compare groups at each moment. For all of the analyses, we considered 5\% as the level of significance and used GraphPad Prism (version 5.01, GraphPad, La Jolla CA).

\section{Results}

All of the animals were healthy at the beginning of the experiment, and none of them showed any adverse reaction while being infused with medications or fluids.

\section{Hematocrit}

The SS group exhibited lower hematocrit values compared to the HEMO group at the moment when catecholamines were administered. After the volemic replacement, the HEMO group showed significantly higher hematocrit values compared to the other groups.

TABLE 2 - The means and standard errors for values in the four groups at different times.

\begin{tabular}{|c|c|c|c|c|c|c|c|}
\hline & Basal & Hemorrhagic & Catecholamine & Volemic replacement & Control 30' & Control 60' & Control 90' \\
\hline Hemo & $35.1 \pm 0.19$ & $33.9 \pm 1.07$ & $32.1 \pm 0.88$ & $34.8 \pm 1.17$ & $35.8 \pm 1.22$ & $35.8 \pm 1.19$ & $35.8 \pm 1.01$ \\
\hline SS & $35.4 \pm 0.22$ & $31.6 \pm 1.98$ & $27.5 \pm 1.56$ & $23.6 \pm 1.17$ & $24.8 \pm 0.94$ & $25.9 \pm 1.15$ & $26.2 \pm 0.98$ \\
\hline ISP & $34.9 \pm 0.29$ & $32.6 \pm 0.73$ & $30.2 \pm 0.72$ & $24.3 \pm 0.57$ & $26.0 \pm 0.55$ & $27.9 \pm 0.83$ & $28.0 \pm 0.61$ \\
\hline FNL & $36.5 \pm 0.11$ & $33.8 \pm 1.35$ & $30.4 \pm 1.12$ & $24.5 \pm 1.41$ & $27.4 \pm 1.3$ & $27.9 \pm 1.16$ & $28.6 \pm 1.16$ \\
\hline
\end{tabular}




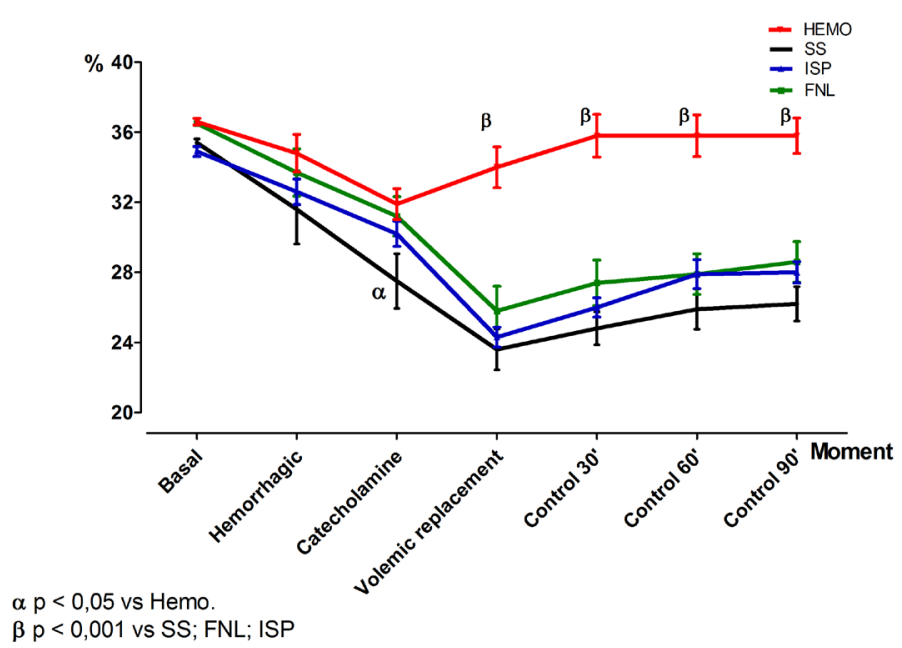

FIGURE 1 - Variations in hematocrit for the four experimental groups.

Heart rate variability

Normalized high frequency

TABLE 3 - Normalized high frequency (\% HF). The mean and standard errors of the values in the four groups at the different times in the study are presented.

\begin{tabular}{lcccc}
\hline & Basal & Hemorrhage & Catecholamines & Control \\
\hline Hemo & $97.5 \pm 0.720$ & $98.7 \pm 0.843$ & $99.0 \pm 0.197$ & $96.3 \pm 1.23$ \\
SS & $97.5 \pm 0.720$ & $94.9 \pm 3.17$ & $98.5 \pm 0.347$ & $93.3 \pm 0.903$ \\
ISP & $98.4 \pm 0.418$ & $99.2 \pm 0.233$ & $97.3 \pm 0.709$ & $98.9 \pm 0.406$ \\
FNL & $98.6 \pm 0.286$ & $99.5 \pm 0.0880$ & $99.3 \pm 0.143$ & $89.8 \pm 1.89$ \\
\hline
\end{tabular}

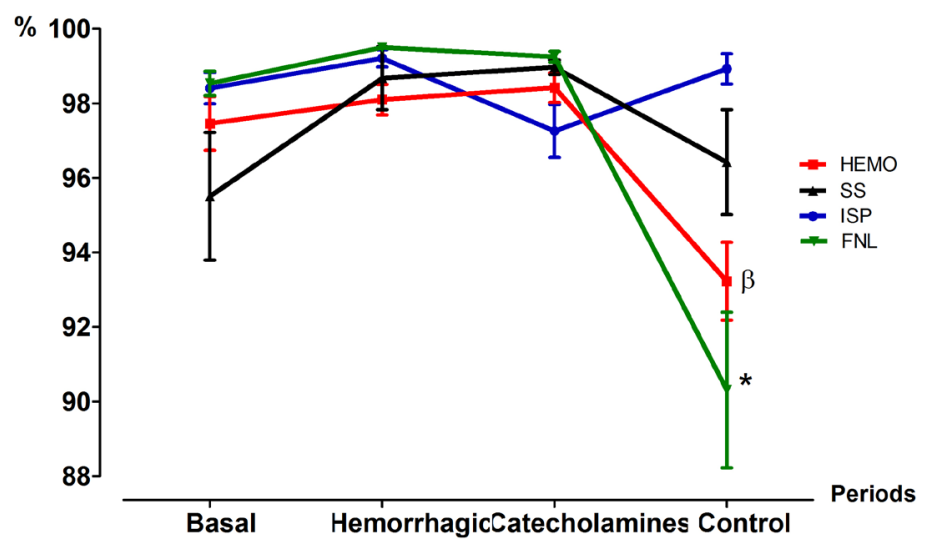

$$
{ }^{*} p<0,05 \text { vs ISP; SS }
$$$$
\beta p<0,05 \text { vs ISP }
$$

FIGURE 2 - Percentages of the high frequency band for heart rate variability.

At the time of control, post-volemic replacement, there was a difference in the ISP group compared to the HEMO and FNL groups. There was also a difference in the SS group compared to the FNL group.

\section{Normalized low frequency}

TABLE 4 - Normalized low frequency ( $\%$ LF). The mean and standard errors of the average values of the four groups at different times during the study are presented.

\begin{tabular}{lcccc}
\hline & Basal & Hemorrhage & Catecholamines & Control \\
\hline Hemo & $2.54 \pm 0.720$ & $1.70 \pm 0.32$ & $1.58 \pm 0.40$ & $6.77 \pm 1.04$ \\
SS & $4.49 \pm 1.71$ & $1.32 \pm 0.84$ & $1.03 \pm 0.20$ & $3.58 \pm 1.41$ \\
ISP & $1.59 \pm 0.418$ & $0.79 \pm 0.233$ & $2.74 \pm 0.71$ & $1.07 \pm 0.41$ \\
FNL & $1.44 \pm 0.286$ & $0.50 \pm 0.09$ & $0.75 \pm 0.14$ & $9.69 \pm 2.09$ \\
\hline
\end{tabular}

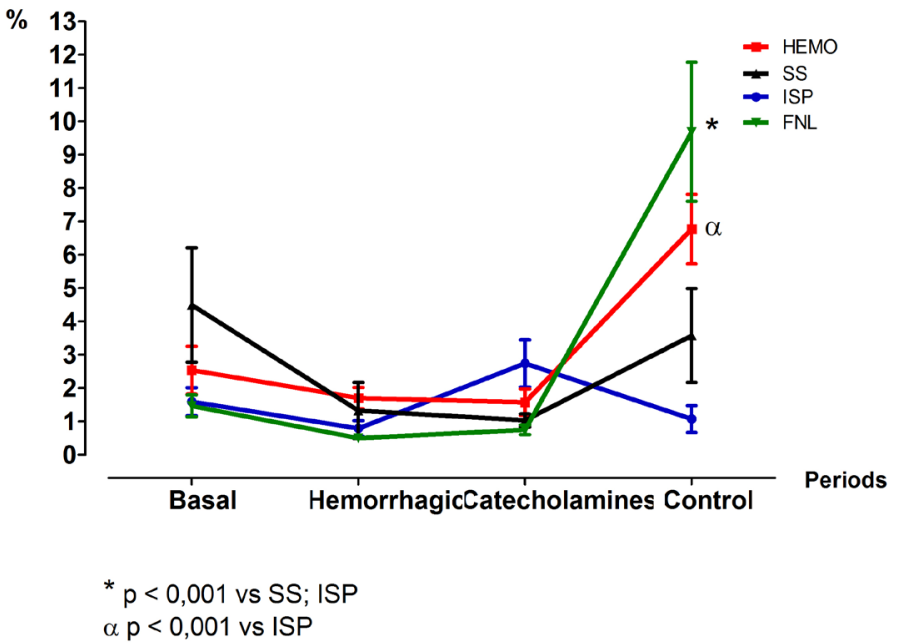

FIGURE 3 - Percentages of the low frequency band for heart rate variability.

At the time of control, post-volemic replacement, there was a difference between the HEMO and FNL groups compared to the ISP group. There was also a difference in the SS group compared to the FNL group at the time of control, post-volemic replacement.

TABLE 5 - The ratio between low frequency and high frequency $(\mathrm{LF} / \mathrm{HF})$. The mean and standard errors of the average values of the four groups at different times during the study are shown.

\begin{tabular}{lcccc}
\hline & Basal & Hemorrhage & Catecholamines & Control \\
\hline Hemo & $0.018 \pm$ & $0.026 \pm$ & $0.050 \pm 0.0205$ & $0.016 \pm$ \\
& 0.00374 & 0.00678 & & 0.00510 \\
SS & $0.018 \pm$ & $0.010 \pm$ & $0.014 \pm 0.00510$ & $0.028 \pm$ \\
& 0.00374 & 0.00316 & & 0.0136 \\
ISP & $0.020 \pm$ & $0.006 \pm$ & $0.012 \pm 0.002$ & $0.016 \pm$ \\
& 0.00707 & 0.00245 & & 0.004 \\
FNL & $0.016 \pm$ & $0.00800 \pm$ & $0.00800 \pm 0.002$ & $0.076 \pm$ \\
& 0.004 & 0,002 & & 0.0211 \\
\hline
\end{tabular}




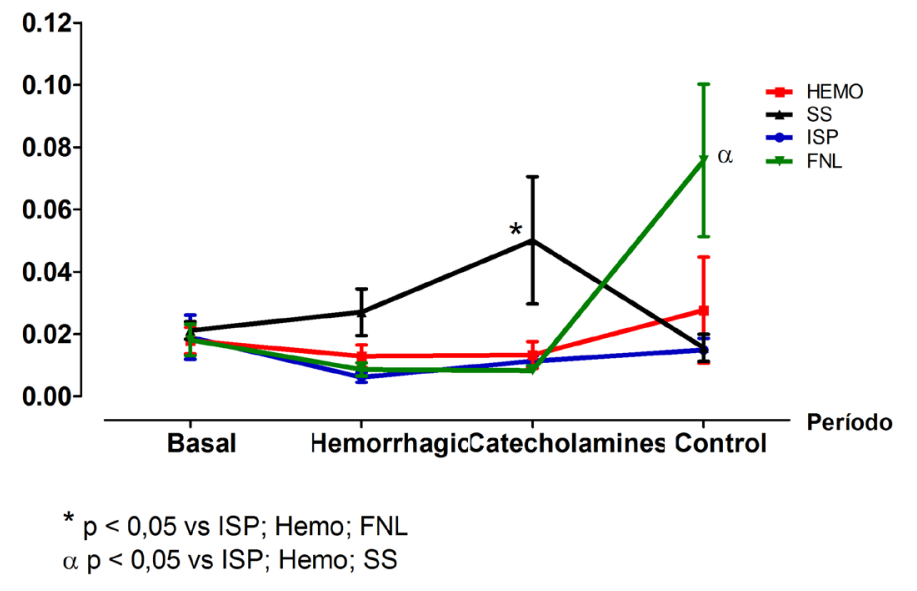

FIGURE 4 - The ratio between the low frequency and high frequency $(\mathrm{LF} / \mathrm{HF})$ of heart rate variability.

\section{$\mathrm{LF} / \mathrm{HF}$ ratio}

For the LF/HF ratio, which characterizes the balance between the sympathetic and parasympathetic components of the ANS, we observed differences between the SS group and the other groups during catecholamine administration. At the time of the control, the post-replacement FNL group showed the highest LF/ HF ratio of all the other groups.

\section{Discussion}

Perioperative fluid therapy in the critical patient ultimately aims to restore blood volume to provide a quantity of dissolved oxygen $\left(\mathrm{DO}_{2}\right)$ at the tissue level that is adequate for systemic metabolic necessities.

Here, we used crystalloid solutions or blood products for perioperative fluid therapy. Below a critical level of hemoglobin at which oxygen-carrying capacity is significantly impaired, the transfusion of red blood cells is the best option for providing $\mathrm{DO}_{2}$. Therapy that re-establishes an adequate supply of oxygen to the tissues is often accompanied by the administration of inotropic or vasoactive solutions. In this situation, Vane et $a l .{ }^{6}$ studied the influence of $\alpha$-, $\beta$ - and dopamine agonist catecholamines on the behavior of the dynamics of crystalloid solutions that had been infused into conscious, normovolemic sheep. These authors concluded that $\beta$ - and dopamine agonist catecholamines in crystalloid solutions maintained intravascular volume but that $\alpha$-agonist catecholamines significantly depleted intravascular volume with a diuretic effect that was significantly greater than that of $\beta$-agonist catecholamines.

These results appear paradoxical because it was expected that vasodilator catecholamines (e.g., dopamine and isoprenaline) would behave differently, reducing systemic vascular resistance and arterial capillary tonus as well as increasing capillary hydrostatic pressure and interstitial filtration. One possible explanation for this phenomenon is that the vasodilating effects of catecholamines increased lymphatic pumping, which rapidly returned interstitial liquid to the circulation. Another possibility is the reduction of systemic vascular resistance by $\beta$-agonists, which results from the opening of a larger number of capillaries and causes the theoretical increase in intracapillary hydrostatic pressure to be dissipated by an increase in microcirculatory surface area. Phenylephrine might promote vasoconstriction more at the price of a reduction in microvascular surface than through an increase in systemic vascular resistance.

Other authors have explained the above phenomenon as a possible effect of $\beta$-agonist drugs on the reduction of the hydraulic conductivity of the microvascular barrier and attribute this effect to an increase in AMPc. They have also demonstrated that $\beta$-agonists block the increase in capillary permeability that is caused by the inflammatory response ${ }^{11-12}$.

Other factors, such as atrial natriuretic peptide and cerebral natriuretic peptide, which stimulate baroreceptors and lead to an increase in sympathetic activity and the activation of the renin-angiotensin-aldosterone system are involved in the dynamic transport of organic fluids ${ }^{13}$. Despite these earlier findings, our study did not show an intravascular retention of crystalloid solutions upon the administration of $\beta$-agonist drugs. Since we studied the effect of the intravascular retention of crystalloids in animals that had been subjected to hemorrhagic shock, this could have led to the liberation of inflammatory mediators that exert a direct influence on the vascular endothelium ${ }^{14-16}$.

Surgical stress or stress from tissue hypoxia as a result of a reduction in $\mathrm{DO}_{2}$ due to a hemorrhagic shock leads to the liberation of inflammatory mediators ${ }^{14-16}$, which provokes a reduction in endothelial glycocalyx and leads to an increase in platelet aggregation ${ }^{17}$, leukocyte adhesion to the endothelial surface $^{18}$ and endothelial permeability, causing tissue edema ${ }^{19-20}$. According to experimental ischemia-reperfusion studies ${ }^{19-21}$, proteases $^{11}$, tumor necrosis factor alpha ${ }^{22}$, free oxygen radicals ${ }^{17}$ and atrial natriuretic peptide degrade the endothelial glycocalyx.

The behavior of the crystalloid solutions in the present study did not duplicate the dynamics of the study that was performed by Vane et al. ${ }^{6}$ because we analyzed hydric retention in animals that had already been exposed to the systemic inflammatory process that stemmed from hemorrhagic shock.

Research in the last three decades has emphasized the importance of the influence of the ANS on the cardiovascular apparatus for the prognosis of cardiac morbi-mortality in patients 
with other chronic co-morbidities and in response to the acute phase of trauma ${ }^{23-25}$.

Evidence has shown a propensity for the association of lethal arrhythmias with increases in sympathetic tonicity and/ or reductions in vagal activity. For this reason, the scientific community has made efforts to qualify and quantify markers of autonomic activity. HRV, which has been studied using different stratification methods, is the marker with the greatest correlation to autonomic influence on the cardiovascular apparatus ${ }^{26}$.

From a physiological point of view, vagal tonus prevails during rest ${ }^{27}$, and variations in the $\mathrm{RR}$ interval are dependent on parasympathetic modulation ${ }^{28}$. Sympathetic and vagal activities constantly interact in heart tissues and are responsible for the control of the HR As a result of the large concentration of acetylcholinesterase in the sinoatrial node, the duration of the vagal stimuli is short due to the rapid hydrolysis of acetylcholine. The physiological predominance of the parasympathetic nervous system over the sympathetic nervous system can be explained by two mechanisms: 1) acetylcholine reduces the liberation of norepinephrine due to sympathetic activity and 2) acetylcholine attenuates the response of the adrenergic stimulus.

Physiological mechanisms of compensation for hypovolemia include an increase in heart rhythm and peripheral vascular resistance. This autonomic compensation occurs by the removal of parasympathetic tonus and the activation of efferent sympathetic neuronal traffic. In experimental models of hypovolemic shock in animals, two phases of autonomic compensation have been observed: 1) the predominance of adrenergic discharge, which results in the maintenance of arterial pressure and perfusion of central organs at the cost of vasoconstriction and 2) the exhaustion of sympathetic tonus, which results in vasodilatation, bradycardia and cardiovascular collapse $\mathrm{e}^{29-30}$.

Other studies have shown that healthy patients subjected to simulated hemorrhage (lower-than-atmospheric pressure on the lower limbs) or the induction of relative hypovolemia in patients subjected to the tilt-table test and an infusion of sodium nitroprusside maintain arterial pressure through the predominance of the sympathetic nervous system, which maintains hemodynamic equilibrium until a certain point, after which an acute reduction in arterial pressure coincides with the fall of the sympathetic traffic ${ }^{31-32}$.

The results of the studies mentioned above suggest that the capacity for compensation of sympathetic modulation in situations of simulated hemorrhage is a prerequisite for hemodynamic recovery during the hemorrhagic process.

In this study, we observed the behavior of HRV in the frequency domain in rabbits that had been subjected to hemorrhagic shock and for which lost blood volume was replaced with crystalloid solutions combined with $\alpha$ - or $\beta$-adrenergic catecholamines. In the present study, we observed that there was a predominance of the LF component of the HRV in relation to HF component when volemic replacement with crystalloid solutions was combined with $\alpha$-agonist drugs than with $\beta$-agonist drugs, which means that the combination of crystalloid solutions with $\alpha$-agonist drugs (FNL) was associated with a significant predominance of sympathetic activity. The spectral profile of HRV for volemic replacement by crystalloid solutions combined with $\beta$-agonist drugs (ISP) did not show the same spectrum as when combined with $\alpha$-agonist drugs. Low total spectral power, which is an estimate of autonomic tonus, and a low ratio of LF to HF, which is an estimate of parasympathetic predominance, were associated with mortality in 742 patients who were monitored for a period of up to six months in surgical intensive care units ${ }^{33}$. Based on these results Cooke et al. ${ }^{34}$ recommended the use of spectral analysis of HRV, specifically frequency domain analysis, in the prehospital evaluation of patients experiencing hemorrhagic trauma. After the normalization of the spectral bands, they correlated a significant parasympathetic component and a lower sympathetic predominance with higher mortality. They hypothesized that frequency domain analysis is superior to time domain analysis due to the possibility of separating the components of the HRV related to physiological processes.

Based on the above studies and on our finding that there was a higher $\mathrm{LF} / \mathrm{HF}$ ratio and a greater LF power when using $\alpha$-agonist drugs, there might be a possible superiority of $\alpha$-agonist drugs over $\beta$-agonists in combination with crystalloid or colloidal solutions in volemic replacement for victims of hemorrhagic traumas, but larger studies and required to confirm this finding.

\section{Conclusions}

No vascular retention was observed with the use of saline solution in combination with $\alpha$ - or $\beta$-agonists in post-hemorrhagic recovery due to possible endothelial dysfunction that stems from inflammatory factors that are related to hemorrhagic shock. We also noted that phenylephrine better maintained an autonomic response in the face of hemorrhagic stress.

\section{References}

1. ACSCT. Shock, Advanced Trauma Life Support: Program for Physicians, Instructor Manual. In: Alexander RH PH, ed. Advanced Trauma Life Support. Chicago: American College of Surgeons; 1993. p.75-94. 
2. Shoemaker WC. Temporal physiologic patterns of shock and circulatory dysfunction based on early descriptions by invasive and noninvasive monitoring. New Horiz. 1996 May;4(2):300-18. PMID: 8774804.

3. Lamke LO, Liljedahl SO. Plasma volume changes after infusion of various plasma expanders. Resuscitation. 1976;5(2):85-92. PMID: 1028122.

4. Tølløfsrud S, Mathru M, Kramer GC. Hypertonic-hyperoncotic solutions in open-heart surgery. Perfusion. 1998 Sep;13(5):289-96. PMID: 9778711.

5. Tølløfsrud S, Tønnessen T, Skraastad Ö, Noddeland H. Hypertonic saline and dextran in normovolemic and hypovolemic healthy volunteers increases interstitial and intravascular fluid volumes. Acta Anaesthesiol Scand. 1998 Feb;42(2):145-53. PMID: 9509195.

6. Vane LA, Prough DS, Kinsky MA, Williams CA, Grady JJ, Kramer GC. Effects of different catecholamines on the dynamics of volume expansion of crystalloid infusion. Anesthesiology. 2004 Nov;101(5):1136-44. PMID: 15505449.

7. Heart rate variability: standards of measurement, physiological interpretation and clinical use. Task Force of the European Society of Cardiology and the North American Society of Pacing and Electrophysiology. [No authors listed] Circulation. 1996 Mar 1;93(5):1043-65. PMID: 8598068.

8. Fan SZ, Cheng YJ, Liu CC. Heart rate variability--a useful non-invasive tool in anesthesia. Acta Anaesthesiol Sin. 1994 Mar;32(1):51-6. Review. PMID: 8199811.

9. Halliwill JR, Billman GE. Effect of general anesthesia on cardiac vagal tone. Am J Physiol. 1992 Jun;262(6 Pt 2):H1719-24. PMID: 1621830.

10. Kamath MV, Fallen EL. Power spectral analysis of heart rate variability: a noninvasive signature of cardiac autonomic function. Crit Rev Biomed Eng. 1993;21:245-311. PMID: 8243093.

11. Adamson RH. Permeability of frog mesenteric capillaries after partial pronase digestion of the endothelial glycocalyx. J Physiol. 1990 Sep;428:1-13. PMID: 2231409.

12. Baluk P, McDonald DM. The beta 2-adrenergic receptor agonist formoterol reduces microvascular leakage by inhibiting endothelial gap formation. Am J Physiol. 1994 Apr;266(4 Pt 1):L461-8. PMID: 7513964.

13. Levin ER, Gardner DG, Samson WK. Natriuretic peptides. N Engl J Med. 1998 Jul 30;339(5):321-8. PMID: 9682046.

14. Holte K, Sharrock NE, Kehlet H. Pathophysiology and clinical implications of perioperative fluid excess. Br J Anaesth. 2002 Oct;89(4):622-32. PMID: 12393365.

15. Desborough JP. The stress response to trauma and surgery. Br J Anaesth. 2000 Jul;85(1):109-17. PMID: 10927999.

16. Wilmore DW. Metabolic response to severe surgical illness: overview. World J Surg. 2000 Jun;24(6):705-11. PMID: 10773123.

17. Vink H, Constantinescu AA, Spaan JA. Oxidized lipoproteins degrade the endothelial surface layer: implications for plateletendothelial cell adhesion. Circulation. 2000 Apr 4;101(13):1500-2. PMID: 10747340.

18. Constantinescu AA, Vink H, Spaan JA. Endothelial cell glycocalyx modulates immobilization of leukocytes at the endothelial surface. Arterioscler Thromb Vasc Biol. 2003 Sep 1;23(9):1541-7. PMID: 12855481 .

19. Chappell D, Jacob M, Hofmann-Kiefer K, Bruegger D, Rehm M, Conzen P, Welsch U, Becker BF. Hydrocortisone preserves the vascular barrier by protecting the endothelial glycocalyx. Anesthesiology. 2007 Nov;107(5):776-84. PMID: 18073553.

20. Jacob M, Rehm M, Loetsch M, Paul JO, Bruegger D, Welsch U, Conzen P, Becker BF. The endothelial glycocalyx affords compatibility of Starling's principle and high cardiac interstitial albumin levels. Cardiovasc Res. 2007 Feb 1;73(3):575-86. PMID: 17622736.

21. Rehm M, Zahler S, Lötsch M, Welsch U, Conzen P, Jacob M, Becker BF. Endothelial glycocalyx as an additional barrier determining extravasation of $6 \%$ hydroxyethyl starch or $5 \%$ albumin solutions in the coronary vascular bed. Anesthesiology. 2004 May;100(5):121123. PMID: 15114220.

22. Henry CB, Duling BR. TNF-alpha increases entry of macromolecules into luminal endothelial cell glycocalyx. Am J Physiol Heart Circ Physiol. 2000 Dec;279(6):H2815-23. PMID: 11087236.

23. Levy MN. Vagal control of the heart: experimental basis and clinical implications. Armonk, NY: Futura; 1994.

24. Lown B, Verrier RL. Neural activity and ventricular fibrillation. N Engl J Med. 1976 May 20;294(21):1165-70. PMID: 57572.

25. Schwartz PJ, Priori SG. Cardiac electrophysiology: from cell to bedside. Philadelphia: WB Saunders CO; 1990.

26. Heart rate variability for risk stratification of life-threatening arrhythmias. American College of Cardiology Cardiovascular Technology Assessment Committee. [No authors listed]. J Am Coll Cardiol. 1993 Sep;22(3):948-50. PMID: 8354837.

27. Levy MN. Sympathetic-parasympathetic interactions in the heart. Circ Res. 1971 Nov;29(5):437-45. PMID: 4330524.

28. Chess GF, Tam RM, Calaresu FR. Influence of cardiac neural inputs on rhythmic variations of heart period in the cat. Am J Physiol. 1975 Mar;228(3):775-80. PMID: 1115243.

29. Barcroft H, Edholm OG, Michael J, Charper EP. Phosthaemorragic fainting study by cardiac output and forearm flow. Lancet. 1944:489-91.

30. Schadt JC, Ludbrook J. Hemodynamic and neurohumoral responses to acute hypovolemia in conscious mammals. Am J Physiol. 1991 Feb;260(2 Pt 2):H305-18. PMID: 1671735.

31. Cooke WH, Convertino VA. Association between vasovagal hypotension and low sympathetic neural activity during presyncope. Clin Auton Res. 2002 Dec;12(6):483-6. PMID: 12598954.

32. Wallin BG, Sundlof G. Sympathetic outflow to muscles during vasovagal syncope. J Auton Nerv Syst. 1982 Nov;6(3):287-91. PMID: 7169498.

33. Winchell RJ, Hoyt DB. Spectral analysis of heart rate variability in the ICU: a measure of autonomic function. J Surg Res. 1996 Jun;63(1):11-6. PMID: 8661164.

34. Cooke WH, Salinas J, Convertino VA, Ludwig DA, Hinds D, Duke JH, Moore FA, Holcomb JB. Heart rate variability and its association with mortality in prehospital trauma patients. J Trauma. 2006 Feb;60(2):363-70; discussion 370. PMID: 1650849.

\section{Correspondence:}

Luiz Antonio Vane

Avenida São João, 323/72

12242-840 São José dos Campos - SP Brasil

lavane@uol.com.br

Received: June 10, 2014

Review: Aug 12, 2014

Accepted: Sep 11, 2014

Conflict of interest: none

Financial source: none

${ }^{1}$ Research performed at Experimental Laboratory of Anesthesiology, Botucatu Medical School, Sao Paulo State University (UNESP), Brazil. Part of PhD degree thesis, Postgraduate Program in Anesthesiology, UNESP. Tutor: Luiz Antonio Vane. 